\title{
Frames, Vanishing Points and Blindness: Frankenstein and the Field of Vision
}

\author{
Will Greenshields \\ Independent researcher. ORCID: oooo-0o03-1464-7182. \\ Email: willgreenshields88@gmail.com
}

Received January 14, 2017; Revised March 14, 2018; Accepted April 02, 2018; Published May 18, 2018.

\begin{abstract}
Whilst the preponderance of references made in Frankenstein to the instruments and organs of the visual field has been repeatedly acknowledged by the text's readers, little sustained attention has been paid to the field that these instruments and organs both construct and occupy. In this paper we will examine the particularity of this field, outlining its structure (the vanishing points and framing), content (its peculiarities and obscurities) and subjects (their modes of witnessing and blindness). Opening with an analysis of Walton's visual field qua desirous fantasy in light of his reference to "keeping", we closely study the visual fields constructed by the artistic, scientific and profane eyes of Shelley, Frankenstein, Clerval and the monster.
\end{abstract}

Keywords: Frankenstein, aesthetics, ethics.

\section{Introduction}

The moral message of Shelley's Frankenstein is well-established: should the man of science devote himself in too dedicated and frenzied a fashion to a single pursuit, such that all other attachments and affections are left to wither in the shade of indifference, he invites catastrophe. Indeed, just three years after the arrival of the second edition of Shelley's novel this message would receive further reinforcement by the publication of Balzac's La Recherche de l'Absolu - the account of an obsessive alchemical search for the philosopher's stone that leaves its protagonist financially destitute and shorn of family ties. If the conjunction of social isolation and a focussed intellect had previously produced major philosophical reformulations of the subject - perhaps the most significant being Descartes' cogito - there was no telling what new anti-social monsters might be birthed by the injection of an advanced scientific technê. However, if Balzac's tale testifies to the social and subjective unravelling prompted by a project's interminable failure, Shelley's novel presents the reader with the horror of its realisation.

This realisation, according to Anne K. Mellor (1989, p. 126), is a violation of not just a moral doctrine of balance but also an aesthetic credo ${ }^{1}$ - with the latter clearly articulated by Walton:

my day dreams are more extended and magnificent; but they want (as the painters call it) keeping; and I greatly need a friend who would have sense enough not to despise me as romantic, and affection enough for me to endeavour to regulate my mind. (p. 31)

Keeping is defined in the OED (1971) as:

(c) AesthetixMS 2018. This Open Access article is published under a Creative Commons Attribution Non-Commercial 4.0 International License (http://creativecommons.org/licenses/by-nc/4.o/), which permits non-commercial re-use, distribution, and reproduction in any medium, provided the original work is properly cited. For citation use the DOI. For commercial re-use, please contact editor@rupkatha.com. 
the maintenance of the proper relation between the representation of nearer and more distant objects in a picture; hence in a more general sense, "the proper subserviency of tone and colour in every part of a picture, so that the general effect is harmonious to the eye." (p. 1530)

In other words, what Walton and Frankenstein require is the ideal viewer formalised by Renaissance single-point perspective: an eye situated outside the frame that ensures the geometric coherence - and, by extension, moral integrity - of everything inside the frame. ${ }^{2}$ Without such a supervision of creative passions the Romantic tableau of snow-capped peaks and shimmering lakes is marred by a self-described "blot upon the earth" (Shelley, 200o, p. 109) that periodically bounds in and out of sight, horrifying viewers with its "distorted proportions" (p. 185). Even when a viewing point exterior to the frame is posited, its supervision is disregarded: that Walton's sister has watched over his maturation with "gentle and feminine fosterage" (p. 32) and later "regarded"3 his enterprise with "evil forebodings" matters little (p. 28). Furthermore, the social link is perturbed: Walton finds it "impossible to communicate" his own sensations (p. 32).

The dovetailing of moral and aesthetic concerns in Frankenstein has been previously commented upon by critics (most notably by Mellor [1989]) but relatively little attention has been paid to specifically scopic dimension of Shelley's novel - that is to say, the abnormalities of a visual field caused by the failure of "keeping." Whilst Tony E. Jackson (2009) rightly notes that Shelley's "novel is literally thick with images of eyes and elaborately described acts of seeing" (p. 70), these images and descriptions have yet to be closely analysed. In this paper we shall examine the visual field, outlining its structure (its vanishing points and framing) and content (its colour and obscurities).

\section{The Frame and the Vanishing Point}

The problematic construction of the visual field is exemplified by Walton's earlier re-working of the metaphor introduced above: "nothing contributes so much to tranquilise the mind as a steady purpose, - a point on which the soul may fix its intellectual eye." (2000, p. 29) Therefore, the viewer - upon whom the composition's "keeping" relies - is none other than Walton himself. If Walton's references to the soul and intellect clearly align his conception of the viewer with the disembodied and formalised point of pure Cartesian cognition presupposed by the Renaissance science of perspective, the "point" on which this eye is fixed ultimately proves to be the vanishing point par excellence - an asymptotic ideal that despite geometrically organising the visual field always remains out of sight, luring in the viewer precisely by virtue of its inaccessibility: "I shall satiate my ardent curiosity with the sight of a part of the world never before visited" (p. 28). The very structure of the picture - its frame and vanishing point - is owed to the desire of the viewer. This is also true of the picture that hangs over the Frankensteins' mantle-piece - itself the product of a morbid desire: "I gazed on the picture of my mother... It was an historical subject, painted at my father's desire, and represented Caroline Beaufort in an agony of despair, kneeling at the coffin of her dead father." (p. 76) 4 Shelley shows us that what Frankenstein calls a "view of nature" is directed not by the new scientific rationality and objectivity but by subjective desire - a desire that necessarily makes any apparently scientific project the subject of moral and aesthetic concerns. Walton's desire is the desire to see: in his "day-dreams" - notably described as being "vivid" - this imperceptible vanishing point is paradoxically associated with the perfection of vision: "There... the sun is forever visible" and a "wondrous power" belonging only to this vanishing point shall "regulate a thousand celestial observations" (p. 28) just as an external viewer 
would "regulate my mind." In other words, the thing that always remains outside his subjective composition at some unreachable point beyond the horizon is objectivity itself. Walton does not so much desire an object within the visual field as he does the perfectibility of this field itself.

What actually results from Walton's voyage is a disruption of the field of vision. Following the dissipation of "a very thick fog" (p. 34) that blinded his expedition and rendered safe navigation impossible, a remarkable spectacle emerges that causes Walton to reach for his instruments of observation: "a strange sight suddenly attracted our attention... the shape of a man, but apparently of gigantic stature... We watched the rapid progress of the traveller with our telescopes, until he was lost among the distant inequalities of the ice." (pp. 34-5) An eccentricity of Frankenstein's field of vision has intruded into Walton's and their respective vanishing points fuse into a polar monster: "we were on a voyage of discovery towards the northern pole. Upon hearing this [Frankenstein] appeared satisfied, and consented to come on board... [He] is continually on the deck, apparently watching for the sledge that preceded his own." (pp. 35-7)

The mutuality of vanishing points is replicated by the mutuality between viewers. Having longed for a friend "whose eyes would reply to mine" (p. 31) - a dialectical relationship of mutual visibility and identification that assures an imaginary ontology (with the actual, symbolic-real ontology being founded, in a Lacanian fashion, on the inexhaustibility of desire) - and previously found it "impossible to communicate" his desire, Walton is able "to communicate to [Frankenstein] without disguise... I was eagerly led by the sympathy which he evinced, to use the language of my heart; to give utterance to the burning ardour of my soul" (pp. 37-8) - the soul that, we recall, requires a set point onto which it fixes its eye. However, Frankenstein has advanced further down this ruinous path than Walton ("[I] arrive[d]... at the summit of my desires" [p. 57]), he knows that what resides at the latter's vanishing point is not a sunlit upland of immaculate visibility, and so it is little surprise that his first response to Walton's confession is to "place his hands before his eyes", to render both himself blind and, through this action, to "try to suppress" and disguise "his emotion" (p. 38) just as Walton is freely giving voice to his, thereby rendering Walton blind and breaking the link between pairs of eyes that reply to each other. Nonetheless, it is in this inconsistent visual field of blindness, ideal points of visibility and eccentrically sized figures out of keeping with proportion that Frankenstein is reluctantly corralled by Walton into recalling his story.

Before we continue, it is worth mentioning that the stated motivation for Frankenstein's recollection differs in the 1818 and 1831 editions of the text. In the former, Frankenstein tells Walton that "I believe that the strange incidents connected with [my tale] will afford $a$ view of nature, which may enlarge your faculties and understanding." In the latter he asks "Do you share my madness? Have you drank also of the intoxicating draught? Hear me, - and let me reveal my tale, and you will dash the cup from your lips!" (200o, p. 38) Certainly, we could attribute this dramatic shift to the general trend toward depressive fatalism that Mellor (1989, p. 171) identifies in the 1831 text - with Frankenstein irretrievably condemned by some irresistible and exterior source of intoxication that overrides individual will - but it is also, for our purposes, worth noting the shift in senses from sight to taste: gone is the optimistic reference to a novel "view of nature", to be replaced by a substance that, rather than being regarded from a position of exteriority from which the view's keeping could be organised, invades the body, replacing the same "faculties of understanding" that the 1818 text promises to enlarge with a "madness". ${ }^{7}$ Any optimism that Walton might have about the "view of nature" granted by his hyperborean paradise where "the sun is forever visible" should be abandoned. The subject is always implicated and an ideal objective sight is impossible. 
The influence of John Locke's An Essay Concerning Human Understanding (1690) on Shelley's representation of the neonatal subject as a tabula rasa (in opposition to the notion of $a$ priori knowledge) and her account of the monster's education has been discussed at length by critics. What has been overlooked, however, is the distorted echo of Locke's (2000) conception of man as "furnished with the faculties of understanding and will" (p. 75) in Frankenstein's reference to man's "faculties and understanding". The reader will note that Frankenstein speaks only of understanding and the 1818 text's omission of will is re-emphasised by the 1831 text's crushing of will via a madness inducing draught. The self-conscious subject of sight who chooses which passive "point" to "fix his eye" on is brought into question by a desire that dominates will and makes scientific understanding dubious. Of course, for Frankenstein, the true horror of his enterprise first makes itself felt when the realised object of his intellectual gaze stares back at him: "I beheld the wretch... and his eyes, if eyes they may be called, were fixed on me." (p. 61)

\section{Creative Vision}

Let us turn now to the scene of creation and its aftermath since it is here that the particular structure and content of the visual field is most explicitly posited. There are, of course, actually two distinct scenes of creation: the creation of the monster and the creation of the text although, as critics have pointed out, there is significant overlap between the two (not least Shelley's reference to the text as her "hideous progeny" [p. 25]). The metatextual account of creation provided in the 1831 preface is prompted by a question that, according to Shelley, was frequently put to her: "How I, then a young girl, came to think of, and to dilate upon, so very hideous an idea?" (p. 19) This question contains an interesting ocular pun: whilst the verbal construction 'to dilate upon' is used to refer to the act of producing a spoken or written exposition, we also know that the pupil dilates in darkness, expanding in an effort to increase its receptivity to limited light. This prefigures Frankenstein's description of himself as a scientific Sinbad, trapped in a dark cave, groping his way toward "one glimmering, and seemingly ineffectual, light." (p. 57) In Theory of Colours (1810) Goethe writes that

If we keep the eyes open in a totally dark place, a certain sense of privation is experienced. The organ is abandoned to itself; it retires into itself. That stimulating and grateful contact is wanting by means of which it is connected with the external world, and becomes part of a whole. $(2014, \text { p. } 2)^{8}$

We are once again reminded of the moral concern regarding isolation and the lack of keeping that ensues: the progeny of a creator labouring in a dark "solitary chamber" (Shelley, 2000, p. 58) cannot but be hideous. Shelley's eye quite literally "retires into itself" - the text is the dilated transcription of a dream sequence witnessed "with shut eyes" (p. 24). Compare this process to that of Byron who, as Shelley admiringly recollects, brought his written thoughts "successively to us, clothed in all the light and harmony of poetry" (p. 22) - a harmony of form and proportion ('keeping') that the monster lacks.

Prior to the scene of creation internal to the narrative, Frankenstein had previously dedicated himself to a relatively innocuous form of scientific research, presented in terms of the refinement of pre-existing apparatuses that would permit a superior mode of experimentation with and observation of the natural world rather than a scientific rupture that births the unsightly ("at the end of two years, I made some discoveries in the improvement of some chemical instruments" [p. 55]). In contradistinction to his later direction, which both requires and results in a total social isolation, these refinements enhance Frankenstein's social integration; they are 
results that the institution can accommodate and celebrate: "My ardour was indeed the astonishment of the students, and my proficiency that of the masters.... [my discoveries] procured me great esteem at the university." (p. 55) Clearly posited here is an ethical distinction between restrained scholarship and Faustian overreach.

However, it is not long before the point on which Frankenstein's soul fixes its intellectual eye becomes anathema to the recuperative regard of his colleagues: "My attention was fixed upon every object the most insupportable to the delicacy of the human feelings." (p. 56) Indeed, the fixing of attention on a certain locus is repeatedly associated in the text with a paradoxical blindness: such is the extent of his all-consuming preoccupation, Frankenstein eventually comes to ignore the "many beautiful and majestic scenes" extensively described by Shelley, his "eyes fixed and unobserving." (135) Far from achieving his stated intention of altering or improving the "view of nature", Frankenstein as banished it to a point beyond the frame. "During my first experiment," he recalls, "a kind of enthusiastic frenzy had blinded me to the horror of my employment; my mind was intently fixed on the consummation of my labour, and my eyes were shut to the horror of my proceedings." (p. 143) Again, it is "with shut eyes" that creation takes place: this is not the immaculate "view of nature" in which Walton so ardently believes. Furthermore, a certain failure of keeping is also in progress: "the... stars" that Walton grandiosely recruits in his third letter as "witnesses and testimonies of my triumph" (p. 34) do not witness Frankenstein: "[I] soon became so ardent and eager, that the stars often disappeared in the light of morning whilst I was yet engaged in my laboratory." (p. 55) Frankenstein will also later comment that, having quit the company of Clerval in Britain and retired to a grim hovel in order to construct the monster's partner, "I lived ungazed at" (p. 143). The stars, of course, are not just metaphorical witnesses; they are also aids to navigation: they themselves (in Walton's characterisation) see and permit the subject to see. In Frankenstein's laboratory, the stars as divine witnesses are instead replaced by the altogether more Gothic and sickly light of the moon: "the moon gazed on my midnight labours, while... I pursued nature to her hiding places.” (p. 58) As David Ketterer (1979) points out, the moon is "consistently associated with the monster" (p. 69); whenever the monster makes an appearance it is usually under the moon's light: "by the dim and yellow light of the moon..." itself associatively linked to "the dull yellow eye of the creature" - "I beheld the wretch" (Shelley, 2000, pp. 60-1). ${ }^{9}$

The discovery that results in Frankenstein beholding the wretch, seeing the monster, has the paradoxical effect of rendering the eye of the beholder blind. In the steps prior to the pivotal moment of creation Frankenstein busied himself with various unpleasant activities which primarily involved careful observation:

I must also observe the natural decay and corruption of the human body... I saw how the fine form of man was degraded and wasted; I beheld the corruption of death... I saw how the worm inherited the wonders of the eye.... My eye-balls were starting from their sockets in attending to the details of my employment. (pp. 56-8)

However, all the accumulated knowledge of scientific observation is retroactively erased by its result: "this discovery was so great and overwhelming, that all the steps by which I had been progressively led to it were obliterated, and I beheld only the result." (p. 57) The breaking of the boundary between life and death is an epistemological (and, ultimately, ontological) rupture and, as such, it has no history that could explain and recuperate it. It is an absolute break with all that has preceded. According to the ethics of science that Shelley's novel suggests, the scientist's inclination toward radical leaps over gradual improvement and meticulously documented progress will result in calamity. It is precisely Frankenstein's irresponsible haste that leads not just 
to the creation of the monster, but also to the monster's visual monstrosity: "As the minuteness of the parts formed a great hindrance to my speed, I resolved, contrary to my first intention, to make a being of a gigantic stature" (p. 58). A figure fundamentally out of keeping with the order of things has been created and it is here that the ethical and aesthetic doctrines fuse. Following the monster's creation and the retroactive erasure of a history of scientific observation, the very instruments of observation - those same instruments that Frankenstein, in his previous role as a socially responsible scientist, had won social approval by refining - become impossible to see: "the sight of a chemical instrument would renew all the agony of my nervous symptoms. Henry saw this, and had removed all my apparatus from my view." (p. 69)

Frankenstein spends that night in a state of extreme mental discomfort, uneasily inhabiting the cramped environ of the apartment and courtyard, producing a dense and overdetermined knot of Oedipal associations that critics have analysed at length. Dawn heralds the return of conscious vision and a restoration of normative time and space permitted by the sight of a clock and the opening of gates: "Morning, dismal and wet, at length dawned, and discovered to my sleepless and aching eyes the church of Ingolstadt, its white steeple" - here presenting an imaginary association with the familiar sight of the white peaks of the alps - "and clock, which indicated the sixth hour. The porter opened the gates of the court, which had that night been my asylum." (pp. 61-2) It is no coincidence that Frankenstein's next encounter with the monster and another night "suffered" in psychological "anguish" (p. 76) is precipitated by his finding the gates of Geneva shut upon his return:

It was completely dark when I arrived in the environs of Geneva; the gates of the town were already shut; and I was obliged to pass the night at Secheron.... Day dawned; and I directed my steps towards the town. The gates were open[.] (pp. 74-6)

It is also the shutting of gates that ultimately condemns Justine, placing her within the space of the monster: "the gates of Geneva were shut, and she was forced to remain several hours of the night in a barn belonging to a cottage" (p. 81). Of course, as Frankenstein's unhappy trajectory winds toward its polar terminus, the space of the monster, having originally been that of its creator's squalid urban space before being shunted to the exterior of the domestic space (most notably, that of the De Lacey family), will re-extend itself to the most intimate and primal locus of domesticity: the bridal chamber. As with the desirous composition of a picture, interior and exterior are both asserted and rendered problematic.

\section{Seeing Monsters}

Let us return to the aftermath of that famous dreary night in November. Almost immediately after quitting the courtyard, the field of vision is rehabilitated by an unanticipated rendezvous dominated by repeated references to specular identification and recognition:

I perceived Henry Clerval, who, on seeing me, instantly sprung out... "how glad I am to see you!"... Nothing could equal my delight on seeing Clerval; his presence brought back... all those scenes of home so dear to my recollection... "It gives me the greatest delight to see you". (pp. 62-3)

With these eyes that reply to each other in mind, it is tempting to read Frankenstein's description of himself as Clerval's "fellow-pupil" (p. 7o) as another ocular pun. The instability of this visual field - granted by the monster's exclusion - is nonetheless rapidly signalled: 
"But, my dear Frankenstein," continued [Clerval], stopping short, and gazing full at my face, "I did not before remark how very ill you appear; so thin and pale; you look as if you had been watching for several nights."... I dreaded to behold this monster; but I feared still more that Henry should see him. (p. 63)

This perilous fragility is immediately confirmed as the newly restored plane of conscious sight dissolves once again into a feverish dreamscape:

[Clerval] saw a wildness in my eyes for which he could not account... ["]What is the cause of all this?" "Do not ask me," cried I, putting my hands before my eyes, for I thought I saw the dreaded spectre... This was the commencement of a nervous fever... The form of the monster... was forever before my eyes". (p. 64)

Following a crisis in the visual field characterised by wilful blindness ("putting my hands before my eyes") and hallucinatory disturbance, Frankenstein presents his curative transformation in terms of a reconstruction of this field at an elementary level - the cognisance of, and affective response to, the exterior world: “...I recovered. I remember the first time I became capable of observing outward objects with any kind of pleasure" (p. 64) This will not, however, extend itself to an ability to observe chemical apparatuses with pleasure.

We recall that Frankenstein will also respond to Walton's declaration of intent by putting his hands before his eyes. This act becomes a sort of involuntary physical tic repeating itself throughout the novel at moments of heightened emotion, blocking the sight of both the actor and his interlocutor. Having guided Frankenstein through recovery and convalescence, Clerval, again posing as an ideal and socially responsible viewer, his "eyes... always quick in discerning the sensations of others" (p. 69), observes his patient reading the letter that conveys the news of William's death: "Clerval, who had watched my countenance as I read this letter, was surprised to observe [my] despair... I threw the letter on the table, and covered my face with my hands." (p. 73) As an aside, we should note that Clerval designs his own distinct composition: his studies "open a field for the plan of life he had marked out... he turned his eyes toward the East" (pp. 69-70) - the intoxicating vanishing point of many an Orientalist.

Peter Capuano (2015) persuasively argues that critics, in emphasizing the horror of the monster's eye and the contextual significance of the scientist's eye and artificial viewing apparatuses, have overlooked an equally vital body part: the hands. Since both are very obviously required for creation, Frankenstein's profane eyes and hands "rival a Judeo-Christian God's allseeing eyes and clay-molding hands." (Capuano, 2015, p. 30) The importance of both is explicitly signalled by Professor Waldman during the influential discussion he has with Frankenstein: "these philosophers, whose hands seem only made to dabble in dirt, and their eyes to pore over the microscope or crucible, have indeed performed miracles." (p. 53) However, the eyes and hands of Waldman's protégé will do far more than observe and tentatively dabble in the workings of nature: they will intervene. And having in concert produced the monster, the hands turn on the eyes in both a symbolic denial of, and literal retreat from, this act. Like the titular protagonist at the conclusion of Oedipus Rex, the scientist wills the release of blindness as an end to an unbearable scene dominated by corpses and the utter destruction of domestic bliss. We are far from the "all-seeing eyes" of a Judeo-Christian God - who, from an ideal position outside the frame, has produced a composition with its own conflicts between harmony and monstrosity, light and dark.

Interestingly, the monster will himself adopt this act, firstly by mocking the link that his creator naively makes between existence and appearance: "Cursed (although I curse myself) be 
the hands that formed you! Begone! Relieve me from the sight of your detested form.' 'Thus I relieve thee, my creator,' he said, and placed his hated hands before my eyes" (p. 94). The monster here suggests that if an object is out of sight it does not necessarily follow that this object is nonexistent. Frankenstein is clearly receptive to this lesson since, from this point on, he becomes a wandering paranoiac, constantly imagining that the monster, unseen, watches over either him or his family. Frankenstein's disquiet is caused by his realisation that, in the construction of his own visual field, he has himself become the object placed within the visual field of another viewer. No longer standing outside, the man of science has been folded into the nightmarish tableau of his own creation. Fittingly, the roles flip: when the monster beholds the result of his own actions (i.e. his creator's corpse) he mimics Frankenstein's act:

"I look on the hands which executed the deed; I think on the heart in which the imagination of it was conceived, and long for the moment when these hands will meet my eyes, when that imagination will haunt my thoughts no more." (p. 188)

Where Walton had once longed for the perfect vision promised by his polar vanishing point, now Frankenstein's monster expresses his longing for blindness in the face of an intolerable scene. Once again, in accordance with Shelley's aesthetics/ethics, any celebration of "all-seeing eyes and clay-molding hands" is supplanted by hands that commit an act so awful that their primary purpose subsequently becomes that of blinding the eyes.

Expressing a wish to "no longer see the sun and stars" (p. 189) - the stars that had previously witnessed Walton and would themselves become the objects of a scientific witnessing ("a thousand celestial observations") permitted by a "sun [that] is forever visible" - the monster, not content with merely rendering himself blind - Walton is "the last of human kind who these eyes will ever behold" (p. 189) - must also blind any future witness, immolating himself upon a funeral pyre that "may afford no light to any curious and unhallowed wretch." (p. 188) The narrative frame itself - that is, Walton's polar expedition serving as the pretext for the presentation of Frankenstein's story - as the structural element necessary for the visibility of the story contained within the frame, finally testifies only to the ultimate invisibility of the monster at its heart. Upon meeting the latter, Walton's first reaction is to "shut my eyes involuntarily" (p. 186) and, as Mellor (1989) points out, his last response provides no illumination: "Walton's final judgement on the creature is mute. After the creature's impassioned apologia pro vita sua, Walton says nothing." (p. 130) The monster disappears, "lost in the darkness and distance" (p. 189), becoming both the vanishing point ("distance") structuring the reader's visual field and the irresolvable obscurity ("darkness") rendering this field incomplete. Dragged inside the narrative frame by a monstrous point on which the reader fixes their intellectual eye, the interpreter struggles to see an authorial creation that is itself a dilation in the face of an enigmatic scene witnessed "with shut eyes".

\section{Notes}

'The moral doctrine is most clearly posited by Frankenstein himself: "A human being ought always to preserve a calm and peaceful mind, and never allow passion or a transitory desire to disturb his tranquillity. I do not think that the pursuit of knowledge is an exception to this rule. If the study to which you apply yourself has a tendency to weaken your affections, and to destroy your taste for those simple pleasures in which no alloy can possibly mix, then that study is certainly unlawful, that is to say, not befitting the human mind." (Shelley, 2000, p. 59). Unless otherwise stated, all quotations are taken from the 1831 edition. 
${ }^{2}$ Coleridge had also borrowed this term from the world of painting by referring to Shakespeare's characters and plays as being "in keeping" - that is, constituting a congruous whole (see: Foakes, 2010, p. 149).

${ }^{3}$ Emphasis my own. Unless otherwise stated all italicisation of quoted material is my own.

${ }^{4}$ This painting is also exemplary of the novel's topological interaction between interiority and exteriority that we observe in our conclusion. As Christine Berthin (2010) has noted, "[t]he tableau of Beaufort in mourning is repeated throughout the novel: it frames the novel, structuring fate, and intervenes in its content." (p. 102)

${ }^{5}$ This appears in the 1818 edition. See: http://knarf.english.upenn.edu/1818vi/flet $48 . h t m l$

${ }^{6}$ See: http://knarf.english.upenn.edu/1818v1/flet48.html

7 Frankenstein will also refute the charge of madness, insisting that "I am not recording the vision of a madman." (2000, p. 56)

${ }^{8}$ This is not to suggest that Shelley was familiar with Theory of Colours although she had of course read The Sorrows of Young Werther, making the latter part of the monster's education. Given the vivid count of the monster's yellow eyes it is also worth citing Goethe's contention that "yellow is a light which has been dampened by darkness".

${ }^{9}$ Denise Gigante (2000) links the displeasing obscurity of the eye to Edmund Burke's (2015) aesthetic theory - according to which "the beauty of the eye consists, first, in its clearness;... none are pleased with an eye, whose water (to use that term) is dull and muddy." (p. 96) As Gigante (2000, p. 571) notes, the monstrosity derives from a loss of ocular transparency (qua window to the soul) and its replacement by a brute materiality, "a lump of vile jelly" entirely distinct from Elizabeth's "cloudless" "blue eyes" upon which Frankenstein's mother "fixed eyes of wonder and admiration" (Shelley, 200o, p. 43).

\section{References}

Balzac, H. (1999). La recherche de l'absolu. Paris: Le Livre de Poche.

Berthin, C. (2010). 'The melancholy crypt of Frankenstein'. In Gothic hauntings: Melancholy crypts and textual ghosts. London: Palgrave Macmillan. pp. 89-107.

Burke, E. (2015). A philosophical enquiry into the sublime and the beautiful. Oxford: Oxford University Press.

Capuano, P. (2015). Changing hands: Industry, evolution, and the reconfiguration of the Victorian body. Michigan: University of Michigan Press.

Foakes, R. (2010). 'Samuel Taylor Coleridge'. In Paulin, R. (Ed.), Voltaire, Goethe, Schlegel, Coleridge: Great Shakespeareans, vol. III. London: Bloomsbury Arden Shakespeare. pp. 128-171.

Gigante, D. (2000). 'Facing the ugly: The case of Frankenstein'. In ELH, vol. 67, no. 2. Baltimore, The Johns Hopkins University Press. pp. 565-587.

von Goethe, J. W. (2014) Theory of colour. (C. L. Eastlake, Trans.). Cambridge: Cambridge University Press.

Jackson, T. E. (2009). The technology of the novel: Writing and narrative in British fiction. Baltimore: The Johns Hopkins University Press.

Ketterer, D. (1979). Frankenstein's creation: The book, the monster, and the human reality. Victoria: ELS Editions.

Locke, J. (2000). An essay concerning human understanding. In Fuller, G., Stecker, R. \& Wright, J. P. (Eds.), John Locke: An essay concerning human understanding in focus. London: Routledge. pp. 45-185.

Mellor, A. K. (1989). Mary Shelley: Her life, her fiction, her monsters. New York: Routledge. 
Shelley, Mary. (2000). Frankenstein. In Smith, J. M. (Ed.), Frankenstein (case studies in contemporary criticism). Boston/ New York: Bedford/ St Martin's. pp. 19-189.

(1971) The compact edition of the Oxford English dictionary, vol. 1, A-O. Oxford: Oxford University Press.

Will Greenshields is the author of Writing the Structures of the Subject: Lacan and Topology (Palgrave, 2017) and several papers published in journals such as the Oxford Literary Review and Textual Practice. 